\title{
Differences in Transmission Properties and Susceptibility to Long-Term Depression Reveal Functional Specialization of Ascending Axon and Parallel Fiber Synapses to Purkinje Cells
}

\author{
Robert E. Sims ${ }^{1,2}$ and Nicholas A. Hartell ${ }^{1,2}$ \\ ${ }^{1}$ Department of Pharmacology, The School of Pharmacy, University of London, London WC1N 1AX, United Kingdom, and ${ }^{2}$ School of Life and Health \\ Sciences, Aston University, Birmingham B4 7ET, United Kingdom
}

\begin{abstract}
An understanding of the patterns of mossy fiber transmission to Purkinje cells, via granule cell axons, is fundamental to models of cerebellar cortical signaling and processing. Early theories assumed that mossy fiber input is widely disseminated across the cerebellar cortex along beams of parallel fibers, which spread for several millimeters across the cerebellar cortex. Direct evidence for this has, however, proved controversial, leading to the development of an alternative hypothesis that mossy fiber inputs to the cerebral cortex are in fact vertically organized such that the ascending segment of the granule axon carries a greater synaptic weight than the parallel fiber segment. Here, we report that ascending axon synapses are selectively resistant to cerebellar long-term depression and that they release transmitter with higher mean release probabilities and mean quantal amplitudes than parallel fiber synapses. This novel specialization of synapses formed by different segments of the same axon not only explains the reported patterns of granule cell $\rightarrow$ Purkinje cell transmission across the cerebellar cortex but also reveals an additional level of functionality and complexity of cerebellar processing. Consequently, ascending axon synapses represent a new element of cortical signal processing that should be distinguished from parallel fiber synapses in future experimental and theoretical studies of cerebellar function.
\end{abstract}

Key words: cerebellum; long-term depression; synaptic; transmission; granule cell; Purkinje cell

\section{Introduction}

Cerebellar granule cells (GCs) relay afferent, excitatory information from mossy fibers to Purkinje cells (PCs). The axons of GCs ascend into the molecular layer $(\mathrm{ML})$, where they bifurcate to form parallel fibers. These extend laterally for several millimeters in either direction, forming one or two synapses with individual PCs, but each making contact with up to thousands of cells as they cross the cerebellar cortex (Mugnaini, 1983; Napper and Harvey, 1988; Harvey and Napper, 1991; Shepherd et al., 2002). This anatomical framework, enabling the divergence of afferent mossy fiber information along beams of fibers across the cerebellar cortex, underpins classical theories for the operation of the cerebellum (Marr, 1969; Albus, 1971). However, although direct activation of the ML can generate activity along beams of parallel fibers for several millimeters (Vranesic et al., 1994), it may not reliably transmit that information to PCs along the whole length of the parallel fiber (Garwicz and Andersson, 1992). Recent evidence suggests that up to $85 \%$ of parallel fiber synapses to PCs do not

Received Sept. 8, 2004; revised Feb. 4, 2005; accepted Feb. 4, 2005.

This work was supported by the Biotechnology and Biological Sciences Research Council and the Royal Society. We thank lan Martin for his support and advice and Angus Silver, Erik De Schutter, and Alex Thomson for useful comments and suggestions.

Correspondence should be addressed to Dr. N. A. Hartell, Department of Pharmacology, The School of Pharmacy, University of London., 29-39 Brunswick Square, Bloomsbury, London WC1N 1AX, UK. E-mail: nicholas.hartell@ulsop.ac.uk. D01:10.1523/JNEUROSCI.0073-05.2005

Copyright $\odot 2005$ Society for Neuroscience $\quad 0270-6474 / 05 / 253246-12 \$ 15.00 / 0$ generate detectable, excitatory postsynaptic responses (Isope and Barbour, 2002). Moreover, stimulation of the periphery or mossy fibers generates only spatially restricted patches of activity above the mossy fiber termination zone (Eccles et al., 1972; Bower and Woolston, 1983; Kolb et al., 1997; Cohen and Yarom, 1998), with little evidence of synchronized firing between PCs with shared parallel fiber input (Jaeger, 2003). These observations have revitalized speculation that synapses formed by the ascending segment of the axon carry a greater synaptic weight than those formed by parallel fibers and hence play a functionally different role in cerebellar signal processing (Llinas, 1982).

Up to $20 \%$ of all GC synapses to PCs are formed by the ascending segment of the axon (Gundappa-Sulur et al., 1999). Ascending axon synapses have a significantly higher density of vesicles in their presynaptic termini than those made by parallel fibers (Gundappa-Sulur et al., 1999), perhaps suggesting a greater probability of transmitter release (Murthy et al., 1997; Schikorski and Stevens, 2001) (but see Xu-Friedman et al., 2001). The postsynaptic density length of parallel fiber synapses diminishes with distance from the GC soma (Pichitpornchai et al., 1994), and a high variability of glutamate receptor subunit 2 labeling, the predominant AMPA receptor subunit at $\mathrm{GC} \rightarrow \mathrm{PC}$ synapses, has been reported (Zhao et al., 1997). This may indicate a parallel postsynaptic heterogeneity between synapse types.

To date, ascending axon connections have been mostly overlooked in current models of cerebellar cortical processing. Here, we report that there are indeed discernible presynaptic and 
a

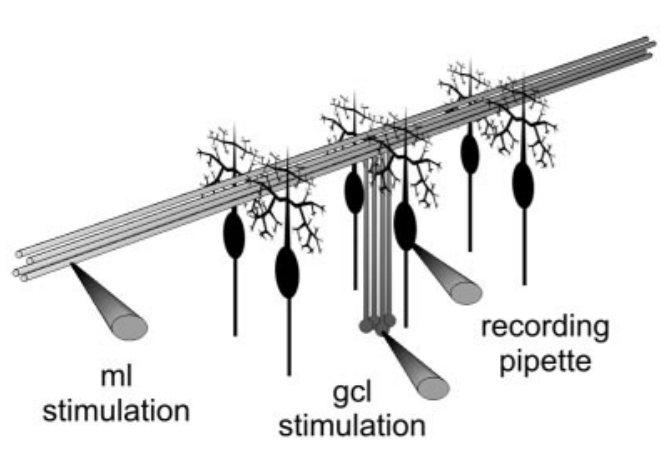

C
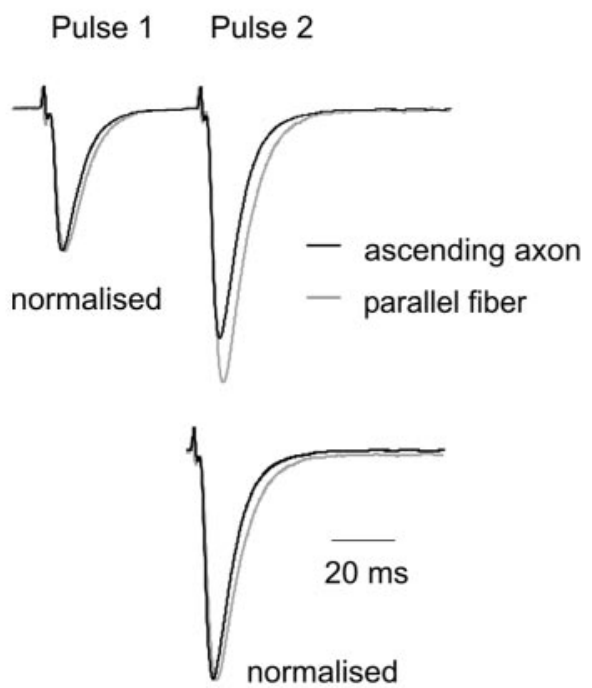

[Potassium gluconate $]_{i}$ b
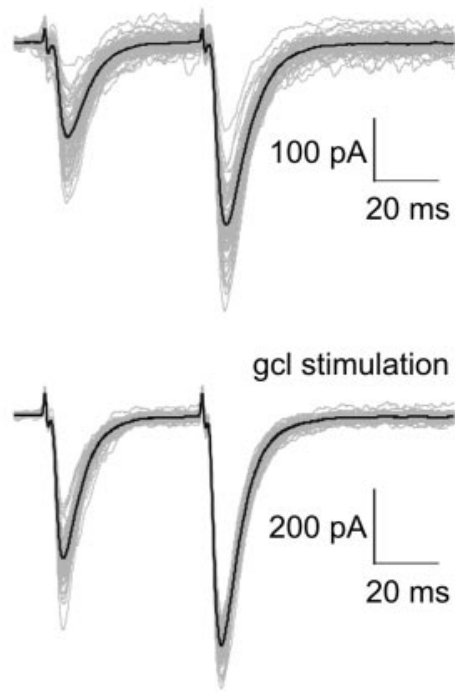

d
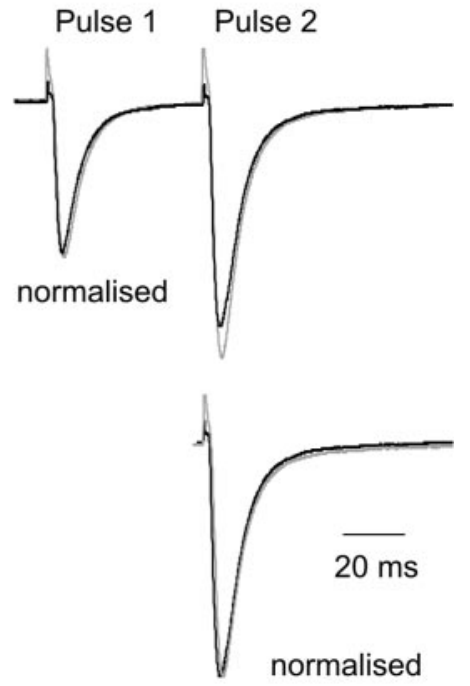

[Cesium methane sulphonate]

Figure 1. Properties of parallel fiber and ascending axon synaptic EPSCs. $\boldsymbol{a}$, The experimental arrangement for independent activation of parallel fiber and ascending axon synapses through stimulation of the ML and GCL in coronal, cerebellar slices. $\boldsymbol{b}$, Representative traces (gray) and their averages (black) to paired-pulse stimulation. $\boldsymbol{c}$, The average responses illustrated in $\boldsymbol{b}$ were normalized to first (top) and second (bottom) peaks to illustrate the elevated PPF at parallel fiber synapses as well as the relative kinetics of ascending axon and parallel fiber EPSCs. GCL EPSCS are shown in black, and parallel fiber EPSCs are shown in gray. Potassium gluconate-based internal recording solutions were used for the experiments shown in $\boldsymbol{b}$ and $\boldsymbol{c}$. In $\boldsymbol{d}$, representative results for a cell filled with a cesium-based solution are illustrated.

postsynaptic transmission differences between ascending axon and parallel fiber synapses to PCs and that synapses formed by the ascending segment of GCs are selectively resistant to cerebellar long-term depression (LTD), a form of synaptic plasticity responsible for learning in the motor system. This differential susceptibility to changes in synaptic strength at different sections of the GC axon provides a mechanism for synaptic specialization, which allows different sections of the same axon to convey different types of information and hence serve different functions.

\section{Materials and Methods}

Preparation of slices. Coronal cerebellar slices (250 $\mu \mathrm{m}$ thick) were prepared from the vermis of 14- to 21-d-old male Wistar rats using a cutting solution containing the following (in $\mathrm{mm}$ ): 250 sucrose, $2.5 \mathrm{KCl}, 26 \mathrm{NaHCO}_{3}, 10$ glucose, $1.25 \mathrm{NaH}_{2} \mathrm{PO}_{4}, 2 \mathrm{CaCl}_{2} \cdot 2 \mathrm{H}_{2} \mathrm{O}$, and 1 $\mathrm{MgCl}_{2} \cdot 6 \mathrm{H}_{2} \mathrm{O}$, equilibrated with $95 \% \mathrm{O}_{2} / 5 \%$ $\mathrm{CO}_{2}, \mathrm{pH}$ 7.4. Slices were incubated at room temperature in an artificial CSF (aCSF) composed of the following (in $\mathrm{mm}$ ): $120 \mathrm{NaCl}, 2.7$ $\mathrm{KCl}, 2.5 \mathrm{CaCl}_{2} \cdot 2 \mathrm{H}_{2} \mathrm{O}, 25 \mathrm{NaHCO}_{3}, 1.2$ $\mathrm{NaHPO}_{4}, 1.2 \mathrm{MgSO}_{4} \cdot 7 \mathrm{H}_{2} \mathrm{O}$, and 11 glucose, equilibrated with $95 \% \mathrm{O}_{2} / 5 \% \mathrm{CO}_{2}, \mathrm{pH} 7.4$. Picrotoxin (Sigma, Poole, UK) was added to the aCSF at a concentration of $20 \mu \mathrm{M}$ to block inhibitory transmission via $\mathrm{GABA}_{\mathrm{A}}$ receptors.

Electrophysiology. Slices were held between nylon nets in an experimental chamber on an upright microscope and perfused with aCSF at a flow rate of $2 \mathrm{ml} / \mathrm{min}$. Whole-cell patch-clamp recordings were made at room temperature from the somata of PCs $20-100 \mu \mathrm{M}$ below the surface of the slice. For recording, patch electrodes (3-5 $\mathrm{M} \Omega$ ) were filled with solutions containing the following (in mM): $132 \mathrm{~K}$-gluconate, $8 \mathrm{NaCl}, 2$ $\mathrm{MgCl}_{2} \cdot 6 \mathrm{H}_{2} \mathrm{O}, 30$ HEPES, $4 \mathrm{Na}_{2} \mathrm{ATP}, 0.3$ $\mathrm{Na}_{3} \mathrm{GTP}, 10$ 1,2-bis(2-aminophenoxy)-ethane$N, N, N^{\prime}, N^{\prime}$-tetraacetic acid (BAPTA), adjusted to $\mathrm{pH}$ 7.3. These levels of BAPTA were used to minimize influences of short- and long-term, calcium-dependent mechanisms of synaptic plasticity originating in the postsynaptic cell. At least 15 min were allowed to elapse after entering whole-cell mode before the start of data collection to enable sufficient diffusion of BAPTA. In a few experiments, a cesium-based internal solution was used of the following composition (in $\mathrm{mM}$ ): $140 \mathrm{CsMeSO}_{3}, 2 \mathrm{MgCl}_{2} \cdot 6 \mathrm{H}_{2} \mathrm{O}, 24$ HEPES, 4 $\mathrm{Na}_{2} \mathrm{ATP}, 0.3 \mathrm{Na}_{3} \mathrm{GTP}, 0.5$ EGTA, and 5 5- $N$-(2,6-dimethyl-phenylcarbamoylmethyl)-triethylammonium bromide (QX314), adjusted to pH 7.3 with $\mathrm{CsOH}$.

In a coronal orientation, the characteristic T-shaped structure of GC axons is preserved, allowing a relatively selective activation of synapses formed by ascending axon segments and by parallel fibers onto PCs (see Fig. 1a). To stimulate ascending axon synapses, an aCSFfilled patch electrode was placed in the slice in the granule cell layer (GCL), 30-100 $\mu \mathrm{m}$ directly behind the PC soma. Because parallel fibers make on average only one or at most two synapses with a single PC (Harvey and Napper, 1991), then in this configuration, the likelihood of activating parallel fiber synapses is small. Although unlikely, we cannot rule out, however, a potential contribution from synapses formed by the parallel fiber very close to the point of bifurcation.

To activate synapses formed by parallel fiber segments of GC axons, a second electrode was inserted midway between the PC layer and pia mater to a depth of 50-100 $\mu \mathrm{m}, 150-300 \mu \mathrm{m}$ lateral to the recorded PC. Ascending axon and parallel fiber pathways were activated alternately at rates of 0.1 or $0.2 \mathrm{~Hz}$. Unless stated otherwise, pairs of stimuli were applied at intervals of $50 \mathrm{~ms}$ at intensities that produced EPSCs with amplitudes of $\sim 100 \mathrm{pA}$ in the standard aCSF containing $2.5 \mathrm{mM} \mathrm{Ca}^{2+}$. 
To compare the properties of synaptic responses at different levels within the ML, EPSCs were characterized according to stimulating positions within a $200 \mu \mathrm{m}$ strip traversing the depth of the ML, starting $50 \mu \mathrm{m}$ from the PC layer. This was to ensure that beams of parallel fibers were activated and not GCs. In some cases, stimulating electrodes were placed $150-$ $300 \mu \mathrm{m}$ lateral to the recorded PC but in the GC layer. In this position, parallel fiber synapses are activated anterogradely, thereby eliminating any possibility of retrograde contamination from ascending axon synapses.

Recordings were made with an Axopatch 200B (Axon Instruments, Union City, CA) amplifier; signals were filtered at $5 \mathrm{kHz}$ (eight-pole Bessel filter), digitized at $10 \mathrm{kHz}$, and stored on a computer using "the LTP program" (Anderson and Collingridge, 2001). EPSC amplitudes and cell input resistances were analyzed on-line. For LTD induction, an intracellular solution containing $0.5 \mathrm{~mm}$ BAPTA was used, and ascending axon and parallel fiber pathways were activated alternately at $0.2 \mathrm{~Hz}$ for at least $10 \mathrm{~min}$, until a stable baseline was established. One of the pathways was then stimulated five times at $100 \mathrm{~Hz}$, followed $100 \mathrm{~ms}$ later by stimulation of the climbing fiber (CF) input. This protocol was repeated 50 times at $2 \mathrm{~s}$ intervals. Stimulation was then resumed at baseline rates. The means of six consecutive sweeps per pathway were calculated every $30 \mathrm{~s}$, and data are expressed as percentages of mean baseline levels. In all experiments, series resistances (5-20 M $\Omega$ ) were compensated $(>80 \%)$ and monitored throughout, and experiments were terminated if series resistance, input resistance, or holding current changed significantly during the experiment. Off-line analysis was performed using Igor Pro software (WaveMetrics, Lake Oswego, OR). EPSC rise and decay times were assessed from the time constants of single exponential curves fitted to each phase $\left(\tau_{\text {rise }}\right.$ and $\left.\tau_{\text {decay }}\right)$.

Analysis. The variance and size of paired-pulse ratios (PPRs) were high at very low stimulus intensities in both pathways. It has been shown recently that calculating the PPR as the mean of individual PPRs is biased in favor of high values because of random fluctuations in response size (Kim and Alger, 2001). Overestimation of actual PPR is more likely when the response size is small and response variance is high. Therefore, to reduce this biasing effect at low stimulus intensities, PPRs were calculated from the ratio of the mean of the second pulses and the mean of the first pulses of at least 10 separate sweeps (Kim and Alger, 2001).

For variance-mean analysis of ascending axon and parallel fiber pathway responses, 50-100 sweeps per pathway were collected alternately at $0.1 \mathrm{~Hz}$ in the standard aCSF and then in solutions containing the following (in $\mathrm{mm}$ ): $5 \mathrm{CaCl}_{2}, 5 \mathrm{CaCl}_{2}$ plus the $\mathrm{A}_{1}$ adenosine antagonist 1,3dipropyl-8-phenylxanthine (DPPX; $100-500 \mathrm{nM}$ ), and $1.25 \mathrm{CaCl}_{2}$. Magnesium levels were adjusted to maintain equivalent divalent ion concentrations. DPPX was used to enhance release probability, because modulation of $A_{1}$ receptors has been shown to primarily alter calcium influx at parallel fiber $\rightarrow$ PC synapses rather than threshold (Dittman and Regehr, 1996). Pairs of stimuli (50 ms separation) were applied per sweep, and data were only included in the analysis once the responses had stabilized between solution changes. Variance-mean analysis was then performed on data collected from individual cells according to published methods (Clements and Silver, 2000). Values for the mean quantal amplitudes $(Q)$, the minimum number of contributing release sites $\left(N_{\min }\right)$, and the average probabilities of release $(P)$ for each pathway were then calculated for each cell, and the mean values were calculated.

A simplified method of variance analysis was used to assess whether long-term changes in synaptic strength at ML or GCL pathways were attributable to changes in $Q, P$, or the number of contributing release sites $(N)$. The mean amplitude and the reciprocal of the square of the coefficient of variation $\left(\mathrm{CV}^{-2}\right)$ of 100-200 individual responses, sampled during a period of stable baseline recording conditions, were calculated. A second set of values was obtained from a stable recording period 25-40 min after pairing one of the pathways with CF stimulation or after control stimulus conditions. The ratios of the second to the first values were calculated to obtain a value relative to baseline conditions, and

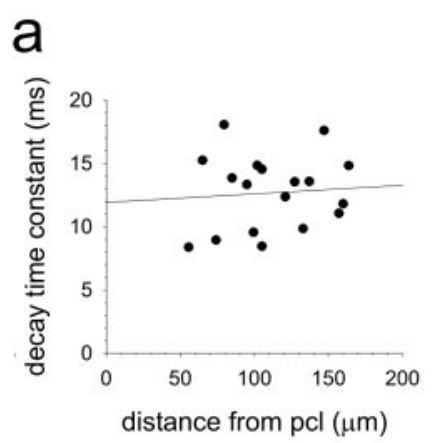

b
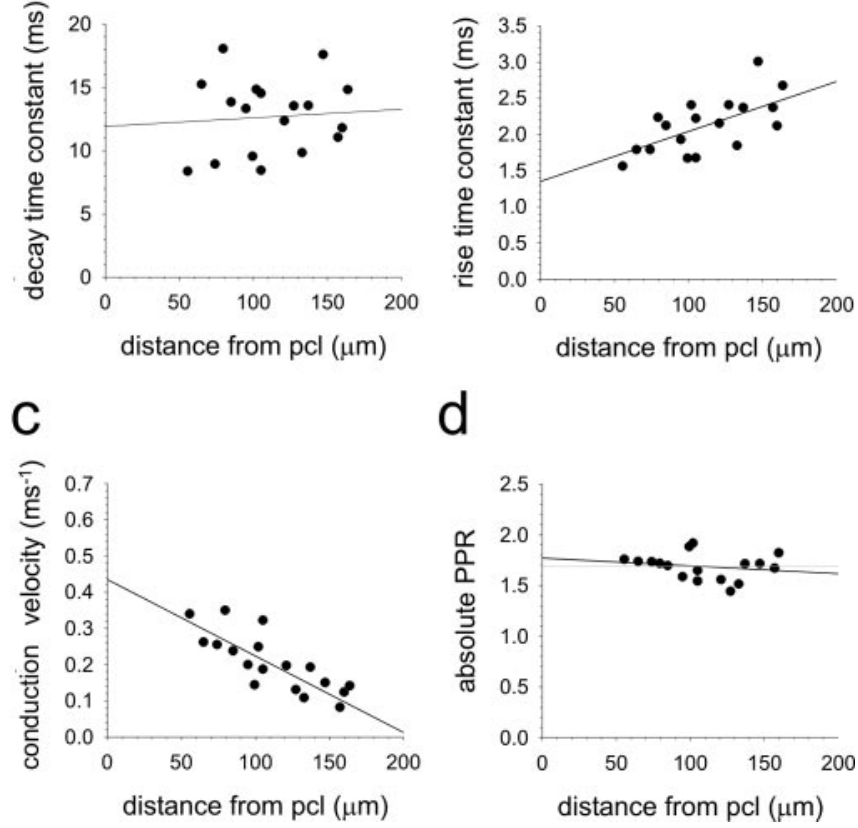

d

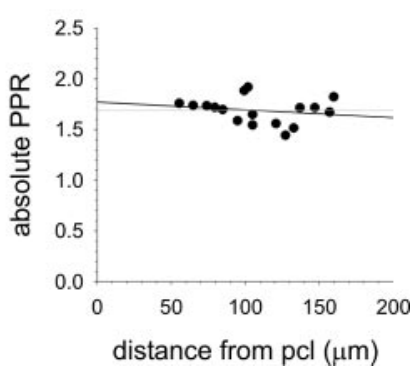

Figure 2. Effects of stimulus position within the ML on parallel fiber $\rightarrow P C$ synaptic characteristics. Whole-cell recordings were made from PCs in coronal slices. Stimulating electrodes were placed at various levels within the ML, and the response characteristics of EPSCs were measured. Conduction velocities were estimated from the latency between stimulus and response and the distance between imaginary lines meeting at right angles between the stimulating and recording electrodes. PCL, Purkinje cell layer.

normalized values of $\mathrm{CV}^{-2}$ were plotted against normalized amplitude. The mean amplitude of the EPSCs represents the product of $N, P$, and $Q$ $(N P Q) . C V^{-2}$ is proportional to $N P / 1-P$. Therefore, a change in $Q$ is independent of $C V^{-2}$, whereas a change in $N$ will be directly proportional to amplitude and $\mathrm{CV}^{-2}$. Unless stated otherwise, all compounds were obtained from Sigma.

\section{Results}

\section{Properties of parallel fiber and ascending axon synapses} to PCs

Whole-cell voltage-clamp recordings were obtained from identified PCs in cerebellar slices cut in a coronal plane. Patch electrodes filled with extracellular solution were placed in the GCL directly below the soma of the PC to activate synapses supplied by ascending segments of the GC axon or 150-300 $\mu \mathrm{m}$ laterally in the ML to activate parallel fibers (for details, see Materials and Methods) (Fig. 1). Initially, pairs of stimuli were applied to each input alternately, and EPSC rise and decay times and the levels of paired-pulse facilitation (PPF) were examined to identify possible differences in synaptic transmission properties between these input pathways. The results of these experiments are summarized in Table 1 and Figure 1. No consistent or significant difference in 


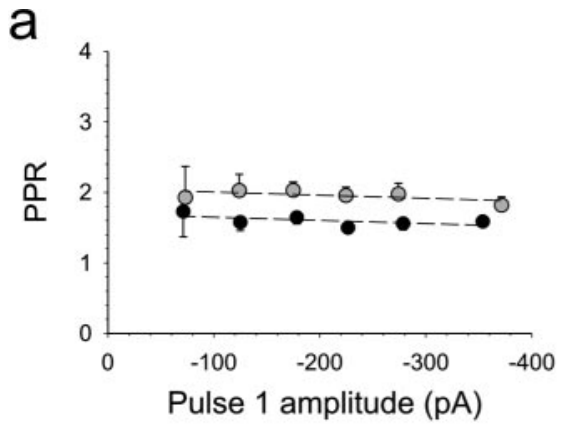

b

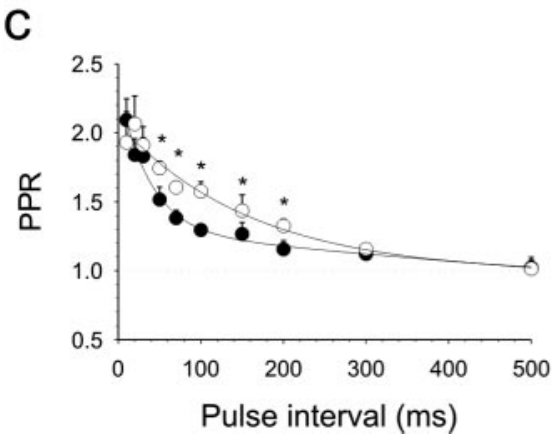

Figure 3. Parallel fiber synapses exhibit enhanced PPF compared with ascending axon synapses. $\boldsymbol{a}$, Pairs of stimuli were applied at 50 ms separations, over a range of stimulus intensities, to the $\mathrm{GCL}$ (black circles) and ML (gray circles). Mean PPRs were plotted against ranges of first-pulse EPSC amplitudes $(n=6)$. An example $(\boldsymbol{b})$ and summary $(\boldsymbol{c})$ are shown of varying the interpulse interval on PPRs elicited by ML and GCL stimulation. $\boldsymbol{b}$, Traces represent the average of 10 consecutive sweeps collected over interpulse intervals of 10-500 ms. c, Mean PPRs were plotted against pulse interval (white circles, ML; black circles, GCL). Asterisks indicate significant differences between pathways $(n=6 ; p<0.05)$. Error bars represent SEM.

a

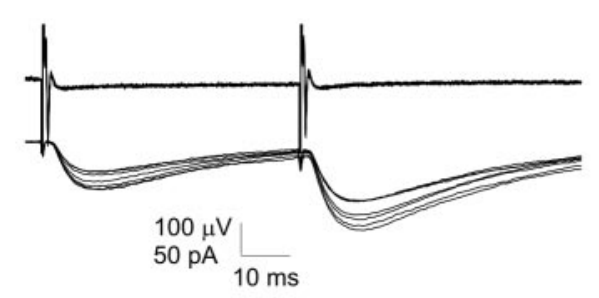

C

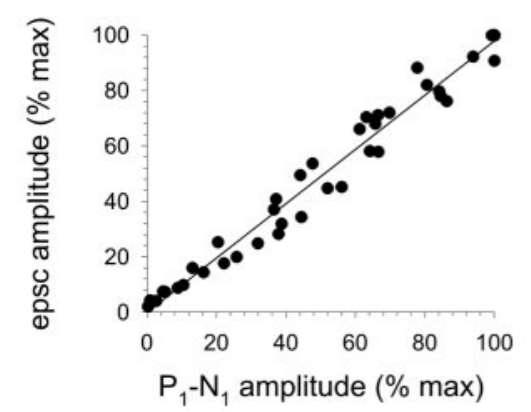

b
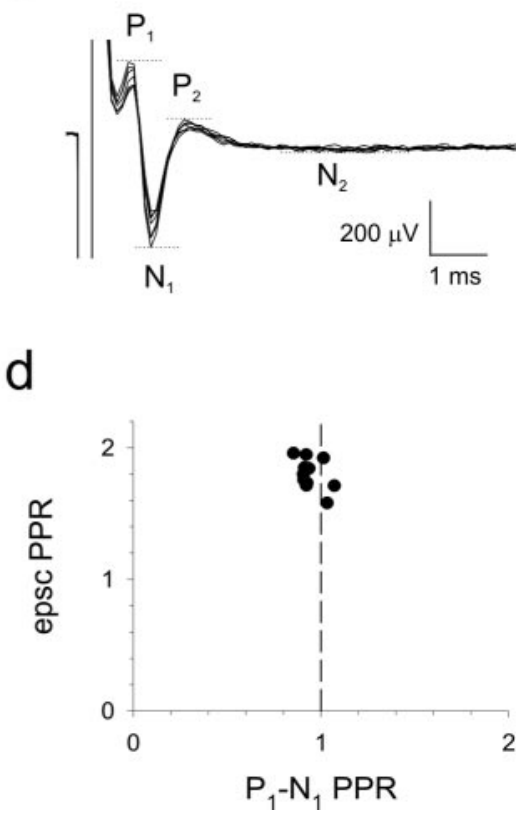

Figure 4. Paired-pulse facilitation is not caused by fiber recruitment. $\boldsymbol{a}$, Simultaneous extracellular field potential measurements combined with whole-cell recordings in response to paired ML stimulation. The means of 10 extracellular (top trace) and intracellular (bottom trace) sweeps recorded at each of five different stimulus intensities are shown. The first extracellular response recorded in $\boldsymbol{a}$ is shown expanded in $\boldsymbol{b}$. The characteristic waveform of extracellular field potentials recorded in the $M L$ can be seen. The amplitude of the positive $(P)$ and negative $(N)$ going peaks $\left(N_{1}-P_{1}\right)$ represents the parallel fiber volley and clearly increases with stimulus intensity; $P_{2}-N_{2}$ represents the synaptic activation of PCs (Eccles et al., 1967). The relationships between the first-pulse EPSC amplitude and $P_{1}-N_{1}$ amplitude at varying stimulation intensities, expressed as a percentage of maximum amplitudes measured in each experiment (c) and between PPRs of EPSCs and the $P_{1}-N_{1}$ fiber volley (d), are shown. Data were collated from a total of five ML pathway inputs to three different cells. the single-exponential decay time constants of EPSCs was observed (ascending axon, $9.3 \pm 0.6 \mathrm{~ms}$; parallel fiber, $8.9 \pm 0.5$ $\mathrm{ms})$. The single-exponential rise time constants of responses to parallel fiber pathway stimulation were, in contrast, significantly longer than those to ascending axon pathway stimulation (parallel fiber, $2.02 \pm$ $0.11 \mathrm{~ms}$; ascending axon, $1.63 \pm 0.08 \mathrm{~ms}$; $p<0.05$; Student's $t$ test; two-tailed; $n=12$ ), as were the respective time to peak amplitudes (3.6 \pm 0.20 and $2.94 \pm 0.14 \mathrm{~ms}$ ).

Parallel fibers tend to form synapses with larger dendrites, on average, than ascending axons (Gundappa-Sulur et al., 1999). Counterintuitively, given the distinctive branching pattern of PC dendrites, larger dendrites tend to be located farther away from the PC soma (Gundappa-Sulur et al., 1999). We therefore undertook experiments to find out whether greater electrotonic filtering at more distant parallel fiber synaptic responses could account for their comparatively slower rise times. Experiments were repeated using cesium-based internal patch solutions containing QX314, and the rise and decay times of parallel fiber and ascending axon EPSCs were examined. These experimental conditions should improve the quality of the voltage clamp and so emphasize any differences attributable to differential filtering. The results of these experiments are also shown in Table 1 and Figure 1. In keeping with a better space clamp, both parallel fiber and ascending axon EPSC decay time constants were shorter but not statistically different from each other. Cesium had no significant effect on EPSC rise times compared with our gluconate-based solution, suggesting that the difference in rise times between pathways was unlikely to be caused by differential filtering.

We next examined whether the position of the parallel fiber stimulating electrode within the ML and hence the level at which the synapses were formed on the PC affected parallel fiber EPSC properties. Because the parallel fibers run parallel to the PC layer, this should activate synapses to the PC at the same level in the ML. Electrodes were placed in the ML, 150-300 $\mu \mathrm{m}$ lateral to the recorded PC cell body in a band 50-200 m from the PC layer. As predicted previously from modeling data (Roth and Häusser, 2001), no correlation between stimulus position and decay time constants was observed (Fig. 2a). EPSC rise times were, however, significantly slower in more superficial regions of the ML (Fig. $2 b)$ ( $p<0.001$; Pearson's correlation). Parallel fibers have different con- 
duction velocities at different levels within the ML (Axelrad and Korn, 1982; Vranesic et al., 1994). We supposed that if ML stimulation recruited a relatively broad beam of parallel fibers with a spread of different conduction velocities, this may lead to a less synchronized activation of the PC, resulting in a slower onset of the population EPSC. Indeed, the latencies from stimulus artifact to EPSC onset increased from deep to superficial regions of the ML, consistent with the presence of finer parallel fiber axons (Fox and Barnard, 1957) with slower conduction velocities (Axelrad and Korn, 1982; Vranesic et al., 1994) in more superficial areas of the ML (Fig. 2c). Because our previous experiments with cesium did not influence rise times at all, we conclude that the slower rise times of parallel fiber EPSCs compared with ascending axon EPSCs most likely result from the activation of parallel fibers with mixed conduction velocities leading to reduced synchronicity of synapse activation, rather than differential electrotonic filtering. Nevertheless, in subsequent experiments, parallel fiber pathway responses were evoked by placing the stimulating electrode within a band no more than $100 \mu \mathrm{m}$ from the PClayer, because in these positions, parallel fiber EPSC kinetics most closely approximated those of ascending axon responses.

\section{Enhanced levels of paired-pulse facilitation at parallel fiber synapses}

$\mathrm{GC} \rightarrow \mathrm{PC}$ synapses characteristically exhibit frequencydependent facilitation (Perkel et al., 1990; Llano et al., 1991), a form of short-term plasticity often observed at excitatory synapses that release transmitter with a relatively low probability (Zucker, 1989; Thomson, 2000). When compared in the same cell, the degree of facilitation at parallel fiber pathways, assessed by calculating the PPR of pairs of pulses separated by $50 \mathrm{~ms}$, was consistently and significantly higher than that at ascending axon pathways (parallel fiber pathway, $1.74 \pm 0.05$; ascending axon pathway, $1.53 \pm 0.04 ; n=41 ; p<0.001$; Wilcoxon signed rank test) (Fig. $1 b, c)$. The degree of facilitation at parallel fiber synapses did not depend on the position of the stimulating electrode within the ML (Fig. 2d) and remained enhanced compared with ascending axon levels when cesium-based internal patch solutions were used (Table 1). PPRs at both pathways were independent of the stimulus intensity (Fig. $3 a$ ), and parallel fiber PPRs were significantly greater than those at ascending axon synapses at pulse intervals between 50 and $200 \mathrm{~ms}$ (Fig. 3b,c). Very little PPF was observed in either pathway at pulse intervals over 200 $\mathrm{ms}$. In the light of the recent observation that GCs fire brief bursts of action potentials at high frequencies (Chadderton et al., 2004), our data suggest that mossy fiber information will be amplified relatively more at parallel fiber synapses to PCs than at ascending axon synapses.

To establish whether enhanced PPF at parallel fibers was synaptic in origin rather than through fiber recruitment as has been suggested previously (Kocsis et al., 1983; Isope and Barbour, 2002), whole-cell recordings of PC responses to paired parallel fiber stimulation were combined with simultaneous extracellular measurements of the parallel fiber volley. Responses were elicited over a range of stimulus intensities to establish the level of change in parallel fiber volley required to double the size of the EPSC. This essentially provides the relationship between volley size and postsynaptic response. From this, we can estimate the relative increase in volley size necessary to account for the enhanced level of PPF if recruitment were the sole cause (Fig. $4 a, b$ ). The postsynaptic response to the first of the two stimuli displayed a direct, linear relationship with the size of the parallel fiber volley (Fig. $4 c$ ). Therefore, as expected, the postsynaptic response increases

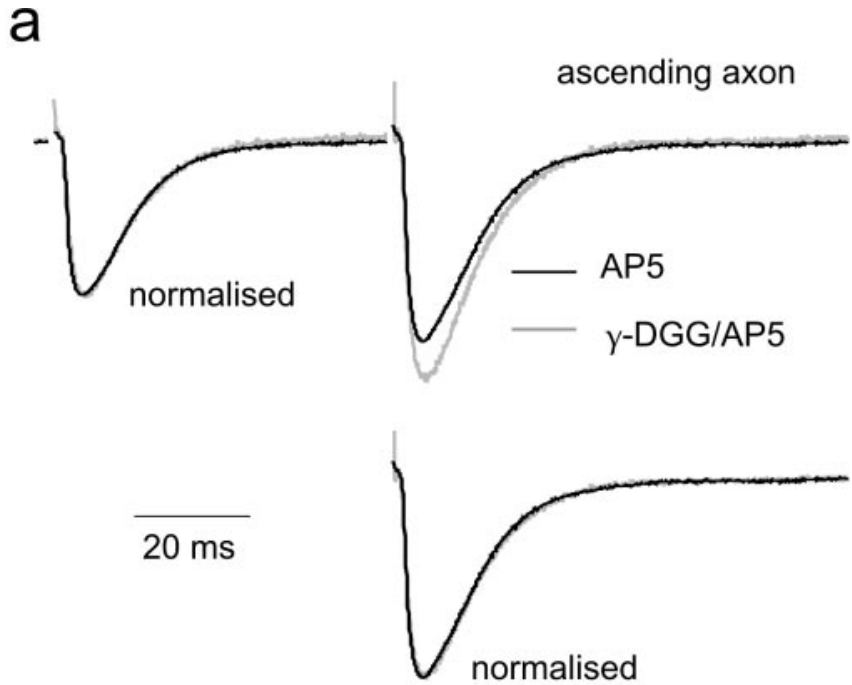

b

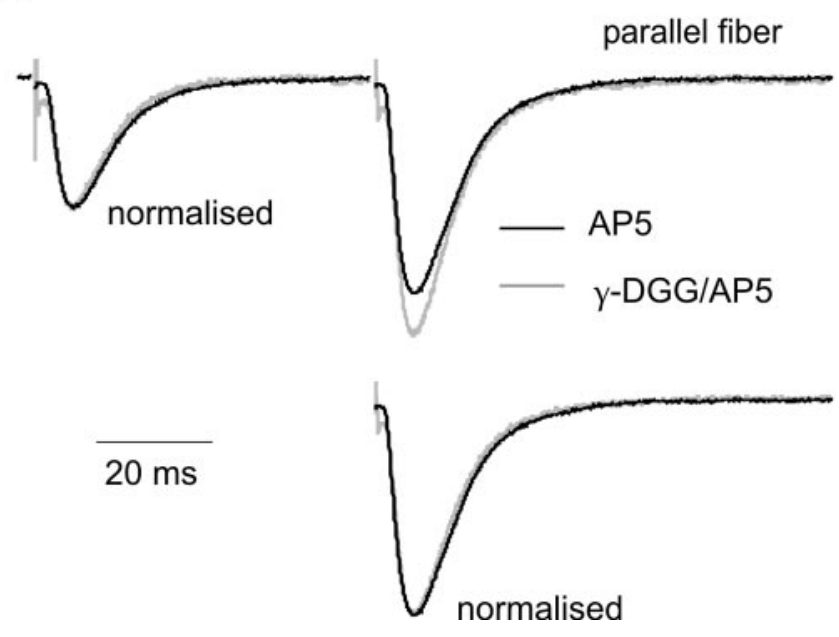

Figure 5. The effects of $\gamma$-DGG on ascending axon and parallel fiber EPSCs. Average responses to at least 30 consecutive responses to ascending axon $(\boldsymbol{a})$ and parallel fiber $(\boldsymbol{b})$ stimulation are shown in the presence of $50 \mu \mathrm{m} \mathrm{AP-5}$ (black traces) and then in the additional presence of $1 \mathrm{~mm} \gamma$-DGG (gray traces). The top set of traces in both panels represents sweeps normalized to the first peak. The bottom traces illustrate the second peaks normalized.

proportionally with the number of activated parallel fibers. In contrast, although the second postsynaptic response displayed facilitation compared with the first, the presynaptic parallel fiber volley did not facilitate at all (Fig. $4 d$ ), even at intensities that yielded EPSC response with amplitudes $>1 \mathrm{nA}$. Thus, at the intensities of stimulation used throughout this study, paired stimulation did not lead to fiber recruitment, and hence we can conclude that it is not a significant contributory factor for the elevated PPRs encountered at parallel fiber synapses.

Stimulation of the ML activates beams of parallel fibers that presumably make contact with a given PC in a fairly localized area (Vranesic et al., 1994). Such a dense activation of several individual synapses in a relatively confined region could lead to excessive or prolonged transmitter release, which might alter EPSC kinetics by influencing transmitter uptake or leading to spillover onto extrasynaptic receptors. A comparison of the waveforms of first and second EPSCs to paired stimulation of either pathway did 
a
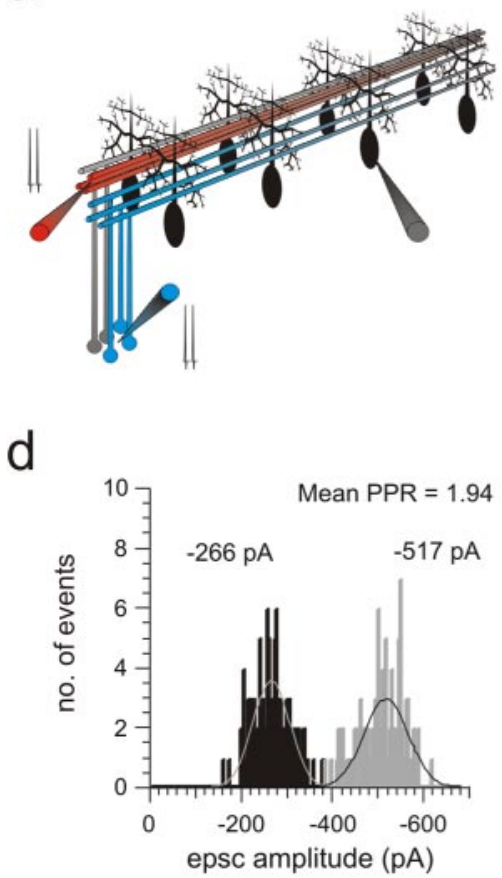

e

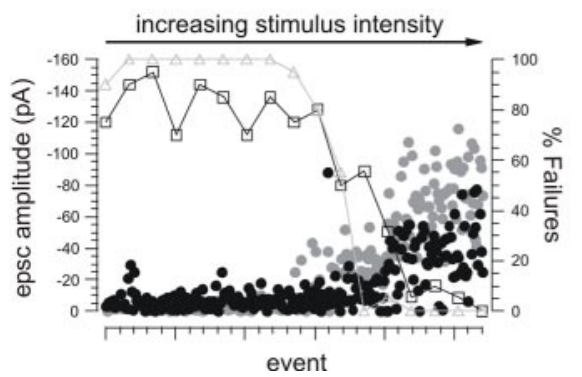

b

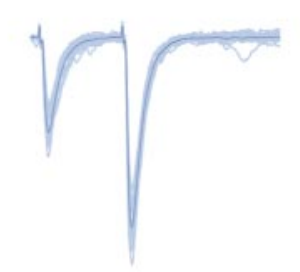

distant gcl stimulation

\section{f}

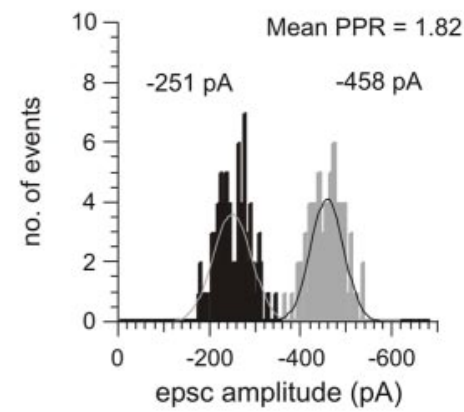

g

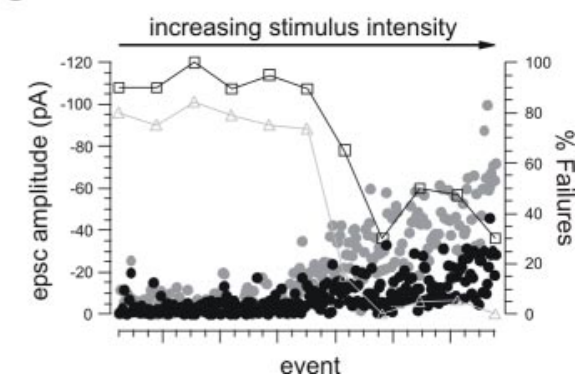

Figure 6. Comparison of the properties of GC $\rightarrow$ PCEPSC elicited by direct and indirect activation of parallel fibers. A schematic diagram illustrating the experimental arrangements for indirect activation of parallel fibers via the granule cell body (blue) and direct activation parallel fibers in the ML (red) is shown in $\boldsymbol{a}$. In both cases, electrodes were placed between 150 and $300 \mu \mathrm{m}$ from the recorded PC body. Representative responses to constant intensity stimulation of the lateral GCL (b) and ML (c) are shown in blue and red. Ten consecutive sweeps, along with their means (darker traces), are shown for each pathway. Frequency distribution plots for constant intensity stimulation of the distant GClayer ( $\boldsymbol{d}$ ) and ML $(\boldsymbol{f})$ for first (black bars) and second (gray bars) EPSC were constructed. The data were constructed from at least 100 sweeps from a single cell. The numbers of events in $3 \mathrm{pA}$ width bins are shown. The ratios of the sample means were calculated by fitting Gaussian curves to the data. Patterns of responses to gradually increasing strengths of stimulation to the lateral $\mathrm{GCL}(\boldsymbol{e})$ and $\mathrm{ML}(\boldsymbol{g})$ are shown below. Paired stimuli (50 ms separation) were applied to each input alternately, and the stimulus intensities were increased incrementally by $\sim 5 \%$ every 20 sweeps. Black and gray circles illustrate the amplitudes of the first and second EPSCs, respectively. Superimposed are the relative percentage failure rates for first (black squares) and second (gray triangles) EPSCS.

not, however, reveal any systematic differences in rise or decay time constants, suggesting no obvious pathway-dependent differences between pulses. Second pulse rise and decay time constants were the following (in ms): ascending axon, $1.67 \pm 0.05$ and $9.37 \pm 0.83 \mathrm{~ms}$; parallel fiber, $1.96 \pm 0.07$ and $9.5 \pm 0.31 \mathrm{~ms}$, respectively. Each pathway was also similarly susceptible to blockade with low concentrations ( $75 \mathrm{nM}$ ) of the AMPA/kainate receptor antagonist 2,3-dihydroxy- 6 - nit ro - 7 - sulfa mo yl-benzo(F)quinoxaline (NBQX; Tocris Cookson, Bristol, UK) (Sheardown et al., 1990). Ascending axon synaptic responses were reduced by NBQX to $64 \%$ of control levels compared with $54 \%$ for parallel fiber responses $(n=4 ; p>0.05$; Wilcoxon matched pairs test) but did not alter the level of PPF in either pathway.

We next examined the effects of the low-affinity, competitive,
AMPA receptor antagonist $\gamma$-D-glutamylglycine ( $\gamma$ DGG; Tocris Cookson) whose efficacy for blocking glutamatergic transmission depends on synaptic glutamate concentration (Clements et al., 1992). Because $\gamma$ DGG can also block NMDA receptors, which are present presynaptically at GC $\rightarrow$ PC synapses, the selective NMDA receptor antagonist DL-2-amino-5-phosphonopentanoic acid (DL-AP-5; Tocris Cookson) was first applied. DL-AP-5 did not affect PPRs or EPSC kinetics at either pathway. Further addition of $\gamma$ DGG reduced ascending axon and parallel fiber pathway EPSC amplitudes by $54.1 \pm 4.7$ and $49.6 \pm$ $5.1 \%$ of baseline values but had no effect on EPSC rise or decay times at either pathway, suggesting that spillover currents do not contribute significantly to either pathway under these conditions of synaptic activation (Fig. 5). $\gamma \mathrm{DGG}$ was less effective against the amplitudes of the second of paired responses at both pathways and hence caused an increase in PPRs. This is expected if, as is thought, PPF represents a presynaptic enhancement of transmitter release. Parallel fiber and ascending axon pathway PPRs were both significantly enhanced compared with control values (111.6 and $108.8 \%$ of control, respectively; Wilcoxon matched pairs test) but remained significantly different from each other, indicating that the enhanced PPF at parallel fiber synapses is not attributable to spillover.

Stimulation of the GCL $150-300 \mu \mathrm{m}$ lateral to the recorded $\mathrm{PC}$ allows the selective excitation of parallel fibers without any possible contribution from retrograde activation of ascending axon synapses (Fig. 6a). Paired stimulation of the distant GCL (Fig. $6 b, d$ ) yielded levels of PPF that were qualitatively and quantitatively indistinguishable from those produced by lateral activation of the ML (Fig. 6c,f). Paired-pulse ratios for responses to lateral GCL and ML stimulation recorded from the same cells were $1.70 \pm 0.04$ and $1.74 \pm$ 0.07 , respectively $(n=9)$. Thus, the selective enhancement of PPF at parallel fiber synapses neither depends on the pattern or density of fiber activation, nor is it a result of retrograde activation of ascending axon synapses.

Activation of single GCs directly below a recorded PC is not only more likely to elicit a detectable response than activation of distant GCs, the responses tend to have larger unitary EPSC amplitudes (Barbour, 1993; Isope and Barbour, 2002). We therefore looked for differences between ascending axon and parallel fiber pathways at or around the threshold for detectable responses. Increasing intensities of stimulation of the ML or the GCL lateral to the recorded PC to activate parallel fibers selectively produced a gradual increase in EPSC amplitudes (Fig. 6e,g), and it was difficult to discern a clear transition between success and failure. In contrast, gradually increasing the intensity of GCL stimulation 
directly below the recorded PC consistently produced a sharp transition between response failure and success (Fig. $7 b, d)$. The mean threshold EPSC amplitude was $-40.6 \pm 6.7 \mathrm{pA}$ (range, -21 to $-88 \mathrm{pA} ; n=10)$. Suprathreshold responses were very reliable, showing little evidence of failure. Additional increases in stimulus intensity produced similar incremental increases in EPSC amplitudes, presumably reflecting the stepwise recruitment of additional single GCs whose ascending axons form synapses with the same cell. We also used a loose patch technique as described previously (Barbour and Isope, 2000) to activate single GCs. The mean EPSC amplitudes of 18 GCs that displayed measurable and reliable paired responses to cell stimulation were -37.1 $\mathrm{pA}$ (range, -6.9 to $-157.1 \mathrm{pA}$ ). These values were similar to those produced by our more simple minimal stimulation technique, suggesting that we were indeed discriminating single GCs. The levels of PPF of responses to minimal stimulation were $1.36 \pm 0.07(n=6)$. Although slightly lower than population responses to GCL stimulation in the same area, they were not statistically different. These very different response characteristics of parallel fiber and ascending axon pathway responses to minimal stimulation raise the possibility that ascending axon synapses may also differ in terms of the number of release sites contributing to transmission and/or the size of the postsynaptic response to a given quantal event.

\section{Variance-mean analysis of parallel fiber and ascending axon synapses}

To help elucidate the source of the differences between ascending axon and parallel fiber pathway synapses to PCs, we undertook a variance-mean analysis of synaptic events. Under each of four experimental conditions designed to alter release probability, the variances of the responses in each pathway were calculated and plotted against the mean EPSC amplitudes (Fig. 8). A parabola was then fitted to the data, and from that the weighted mean release probability, the minimum number of release sites contributing to the response, and the weighted mean quantal amplitude were calculated (Silver et al., 1998; Reid and Clements, 1999; Clements and Silver, 2000).

In all seven cells in which a complete set of data were obtained, the variance-mean relationships of the first of paired EPSC responses to ascending axon and parallel fiber pathways revealed significant differences in synaptic properties. At stimulation strengths that yielded equivalent-sized mean EPSC amplitudes (ascending axon, $-139 \pm 11 \mathrm{pA}$; parallel fiber, $-143 \pm 23 \mathrm{pA}$ ), ascending axon pathway responses yielded values of $Q=-8.5 \pm$ $1.21 \mathrm{pA}$ (mean $\pm \mathrm{SEM}), p=0.44 \pm 0.04$ (in $2.5 \mathrm{mM}$ extracellular calcium), and $N_{\min }=42.5 \pm 6.4$. Parallel fiber pathway responses gave values of $Q=-6.3 \pm 0.9 \mathrm{pA}, p=0.30 \pm 0.03$, and $N_{\min }=$ $84.7 \pm 17.8$. Values for $Q, P$, and $N_{\min }$ were all statistically significantly different $(p<0.05$; Wilcoxon signed ranks test; twotailed; $n=7$ ). The apparent difference in quantal amplitude between ascending axon and parallel fiber pathway synaptic responses might suggest a difference in the amount of transmitter released per synaptic event or a difference in postsynaptic re- sponse to a quantal event, perhaps indicating a difference in receptor number or even subunit composition. As mentioned previously, dendritic filtering could also lead to an underestimate of $Q$ if one set of synapses were systematically located at sites more distant from the point of recording. However, modeling studies suggest that the position of the synapse with respect to the PC dendritic tree has very little influence on EPSC amplitudes (Roth and Häusser, 2001). Other potential sources of error such as systematic differences in series resistance can also be discounted, because pathway responses were always compared in the same cell.

Variance-mean data for the second response of the paired stimuli for both pathways fell on the same parabolic function defined by the first (Fig. $8 c, d$ ). This observation is important because it provides strong evidence that PPF at both pathways results from a presynaptic enhancement of release probability rather than a change in the number of contributing release sites or a change in the quantal amplitude. Together, these data provide clear evidence that the mean probability of transmitter release at ascending axon pathway synapses is greater than that at parallel fiber pathway synapses.

We next examined whether synaptic inputs from parallel fibers and ascending axons to the same cell responded differently to trains of seven stimuli applied at intervals of $50 \mathrm{~ms}$. Under our standard extracellular calcium conditions of $2.5 \mathrm{~mm}$, responses to ML stimulation facilitated until a plateau was reached after the fourth or fifth response. A representative example from a total of five separate recordings is shown in Figure $9 a$. The peak response to GCL stimulation occurred after the second or in some cases the third pulse, with subsequent responses depressing (Fig. 9b). Lowering the probability of release by reducing the extracellular calcium concentration to $1.0 \mathrm{~mm}$ reduced the average amplitude of the initial EPSC in the train as expected but caused a much more pronounced augmentation of successive parallel fiber responses. Under these conditions, ascending axon synapses no longer depressed but facilitated and reached a sustained peak. These data further suggest that under equivalent experimental conditions of 
a

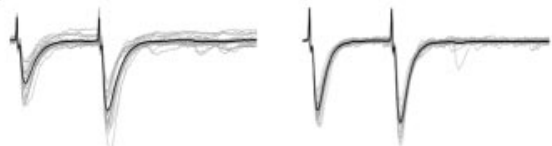

gcl stimulation
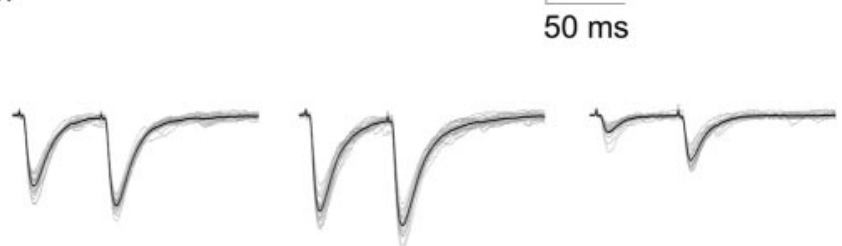

$\mathrm{ml}$ stimulation

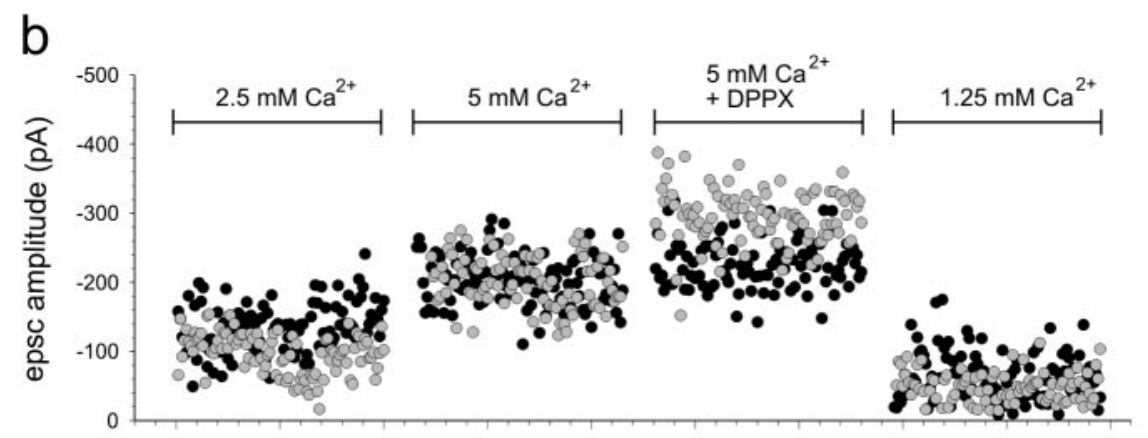

Event

C

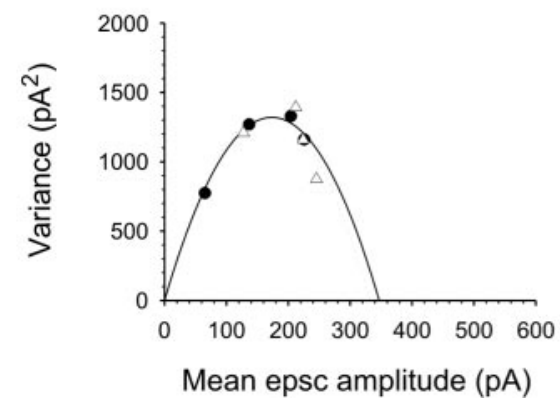

d

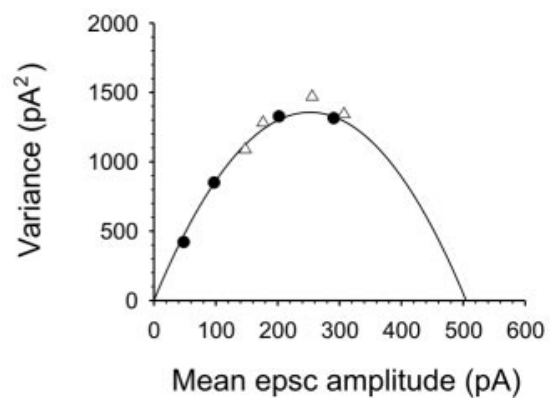

Figure 8. Variance-mean analysis of synaptic responses to alternate stimulation of ascending axon and parallel fiber pathways to a single PC. Examples of 20 individual sweeps (gray lines) along with the calculated mean response (black lines) are shown for each extracellular solution, for ascending axon and parallel fiber pathway stimulation $(\boldsymbol{a})$. The individual amplitudes of the first-pulse responses for all of the data in this experiment are shown below (b). Black circles represent ascending axon pathway responses, and gray circles represent parallel fiber pathway responses. Variance-mean graphs were constructed for the first (black circles) and second (white triangles) EPSC responses to ascending axon ( $\boldsymbol{c}$ ) and parallel fiber (d) pathway stimulation. Values for $N_{\text {min }}$ and $Q$ were obtained.

transmitter release, parallel fibers release transmitter with a lower mean probability than ascending axon synapses. Moreover, the higher probabilities of release encountered at ascending axon synapses are accompanied by a reduced ability to follow repetitive activation of GCs.

\section{LTD is absent at ascending axon synapses to PCs}

Our data so far reveal that differences in quantal amplitude and release probability between axonal segments of the same axon arise, but how might these specializations arise, and what purpose might they serve? Several forms of plasticity at GC $\rightarrow$ PC synapses have been described previously (Hartell, 2002; Ito, 2002). Of these, the best understood is cerebellar LTD, which occurs when
GC activity coincides repetitively with CF activity and results in a postsynaptic reduction in synaptic efficacy, probably via downregulation (Wang and Linden, 2000) or declustering of AMPA receptors (Matsuda et al., 2000). In the event that the lower mean quantal amplitude observed at parallel fiber synapses represented an inherent susceptibility to or was a result of the previous induction of LTD, we compared the abilities of ascending axon synapses and parallel fiber synapses to undergo LTD through conjunctive stimulation with the CF input. Pairing ML stimulation with CF activation produced a clear depression at parallel fiber pathway synapses, but this did not spread to ascending axon pathway synapses (Fig. 10a). Thirty minutes after pairing, ML EPSC amplitudes were $72 \pm 4.5 \%$ of baseline compared with no change (100.3 \pm $10.3 \%)$ for GCL EPSCs $(n=8)$ (Fig. $10 c, e)$. Pairing GCL stimulation with $\mathrm{CF}$ activation, on the other hand, failed to produce a LTD at either pathway (GCL, $95.5 \pm 12.2 \%$; ML, $98.7 \pm 12.7 \% ; n=7$ ) (Fig. $10 b, d, e)$. Therefore, LTD appears to be expressed selectively at parallel fiber synapses.

It is not feasible to apply a full variancemean analysis before and after LTD induction to assess the extent and origins of synaptic changes. Therefore, we used a more simple comparison of the coefficients of variation of synaptic responses before and after LTD and other patterns of control stimulation to both pathways. In this model, the reciprocal of the square of the coefficient of variation of synaptic response is directly proportional to $N P /(1-$ $P)$ and hence independent of $Q$, while $M=$ NPQ (Bekkers and Stevens, 1990; Faber and Korn, 1991). This model can be effective for distinguishing synaptic changes of postsynaptic origin. Figure $10 f$ compares the relative changes in mean amplitude and $C V^{-2}$ with respect to baseline conditions for ML and GCL pathways after each of four different stimulation conditions. The selective depression of ML responses after pairing with CF stimulation was not accompanied by a significant change in $\mathrm{CV}^{-2}$, indicating a postsynaptic origin.

\section{Discussion}

In this study, we tested the hypothesis that differences in the properties of synapses formed onto PCs by ascending and parallel fiber sections of the GC axon provide the basis for this differential weighting of synaptic information. By comparing the levels of short-term facilitation and response variability over a range of release conditions, we provide evidence that ascending axon synapses release transmitter with higher mean release probabilities and mean quantal amplitudes than parallel fiber synapses. Ascending axon synapses were also found to be selectively resistant 
to cerebellar LTD. These results lead us to conclude that synaptic specialization within different segments of the same axon, as a result of the selective induction of plasticity, not only accounts for the reported patterns of $\mathrm{GC} \rightarrow \mathrm{PC}$ transmission across the cerebellar cortex, but also reveals an additional level of functionality and complexity of cerebellar processing. hibit a greater degree of PPF than ascending axon synapses has been alluded to anecdotally, but this difference was formerly attributed to either differential fiber recruitment or transmitter spillover (Isope and Barbour, 2002). Simultaneous measurement of the intracellular EPSC and the extracellular parallel fiber volley revealed that PPF was not accompanied by fiber recruitment, and therefore the difference in PPF between pathways is synaptic in origin. PPF at both pathways was unaffected by the composition of the internal patch solution. Whereas cesium-based internal solutions containing QX314 improve space clamp, our PPR measurements indicate that the space-clamp conditions using potassium gluconate-based solutions, more appropriate for the induction of synaptic plasticity, are adequate for obtaining accurate measurements of amplitude. ascending axon synapses released transmitter with a higher probability than parallel fiber synapses. The fact that variancemean analysis of the second of a pair of stimuli was described by the same parabolic function as the first provides strong evidence that the differences in PPF were indeed attributable to differences in release probability. Variance-mean analysis additionally revealed that ascending axon synapses have higher mean quantal amplitudes and probabilities of transmitter release than those formed by parallel fiber segments of the axon. Weighted mean values for $Q$ and $P$ at ascending axon synapses were estimated to be -8.5 and $0.44 \mathrm{pA}$, respectively (in $2.5 \mathrm{~mm}$ extracellular calcium). Our estimation of release probability is seemingly at odds with the reported single $\mathrm{GC} \rightarrow \mathrm{PC}$ failure rates of $<10 \%$ (i.e., a success probability of $>0.9$ ) (Isope and Barbour, 2002). However, these two ways of expressing synaptic probability are not equivalent. In this study, $P$ represents the mean probability per release site. Using our estimate of $P$ in a simple binomial model of transmitter release, similar failure rates can be obtained if we predict that a given $\mathrm{PC}$ receives, on average, contact from three to four release sites per ascending axon. Evidence for multiple release sites at single synapses does exist at connections between inhibitory neurons in the cerebellum (Auger et al., 1998). GC $\rightarrow$ PC synapses display an average of seven to eight docked vesicles, and although this could indicate multivesicular release, the relationship between docked vesicles, release sites, and release probability is unclear (Xu-Friedman et al., 2001).

Three to four release sites at a single ascending axon synapse, each with a mean $Q$ of $-8.5 \mathrm{pA}$, would produce a theoretical b gcl stimulation $2.5 \mathrm{mM}\left[\mathrm{Ca}^{2+}\right]_{\mathrm{e}}$
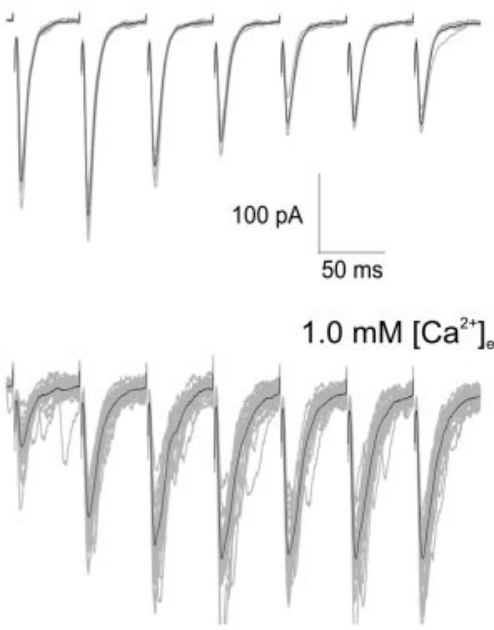

d

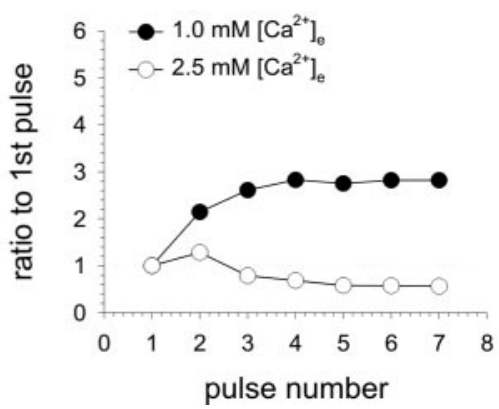

Figure 9. Ascending axon synapses cannot sustain facilitation to trains of stimuli. Single-cell examples illustrating the effects of trains of seven stimuli applied to the $\mathrm{ML}(\boldsymbol{a})$ and $\mathrm{GCL}(\boldsymbol{b})$ in the presence of $2.5 \mathrm{~mm}$ (top) and $1.0 \mathrm{~mm}$ (bottom) extracellular Responses to ML and GCL stimulation under each calcium condition were normalized to the amplitude of the first EPSC and are

The possibility that parallel fibers ex-

Variance-mean analysis confirmed that $1.0 \mathrm{mM}\left[\mathrm{Ca}^{2+}\right]$
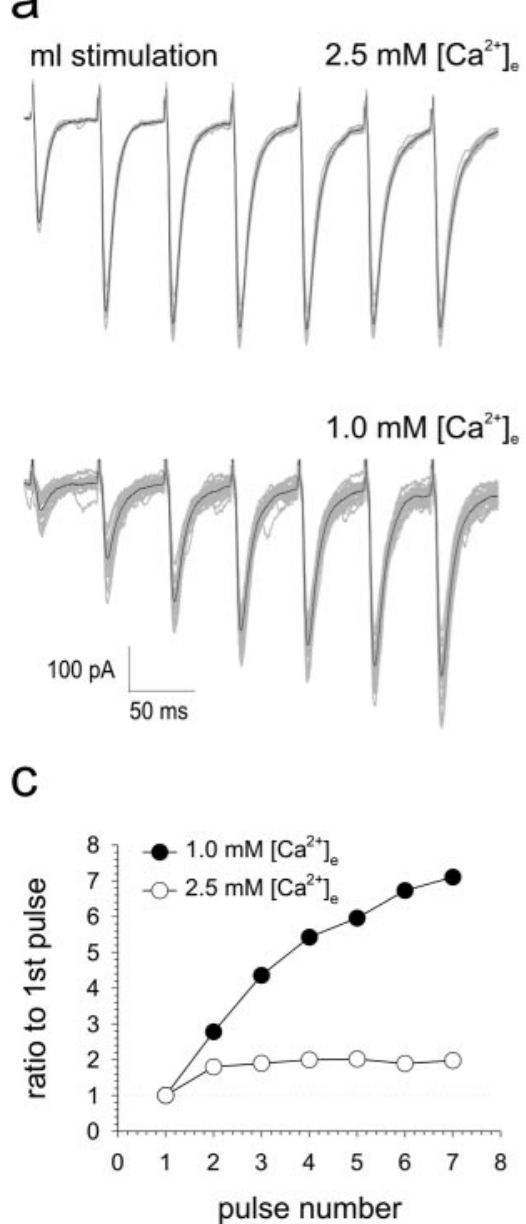

C mean unitary single GC amplitude of between -11 and $-15 \mathrm{pA}$. This is in reasonably close agreement with those produced by stimulation of single GCs adjacent to PC soma (Isope and Barbour, 2002) but somewhat lower than our mean value of $-40.6 \mathrm{pA}$ (range, -21 to $-88 \mathrm{pA}$ ), which is closer to values reported in a previous study from the same laboratory (Barbour, 1993). Such large unitary amplitudes would require release from $>10$ individual release sites. Ascending axons make $\sim 30$ synaptic contacts before forming parallel fibers (Pichitpornchai et al., 1994). Because of their flat structure, there will be little intermingling of adjacent PC dendrites, and so it is it is tempting to speculate that these larger, single GC EPSCs represent ascending axons that make multiple synaptic contacts with a single PC. Applying the same binomial model to our estimated values of $Q$ and $P$ at parallel fiber synapses ( -6.3 and $0.3 \mathrm{pA}$ ), a failure rate of $<10 \%$ requires six to seven release sites, producing a mean EPSC amplitude of between -11 and $-13 \mathrm{pA}$. This is again similar to the values reported by Isope and Barbour (2002) but highlights an important advantage of variance-mean analysis over estimations of failure rate; similar failure rates can be observed at synapses with different release probabilities if the synapses release more than one vesicle at a time. Given that parallel fibers make one and rarely two contacts with a single PC (Harvey and Napper, 1991), this would suggest that parallel fiber synapses are multivesicular. 
a
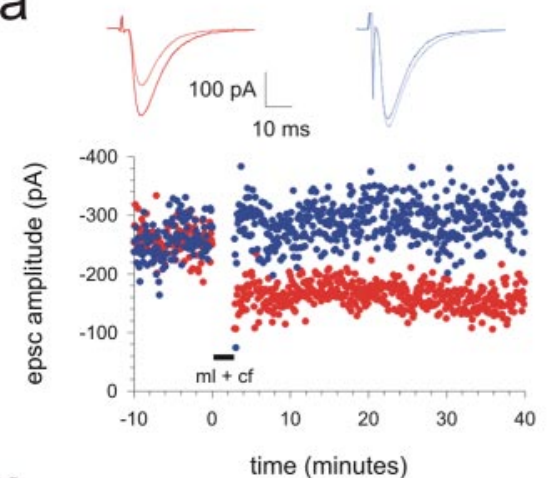

C

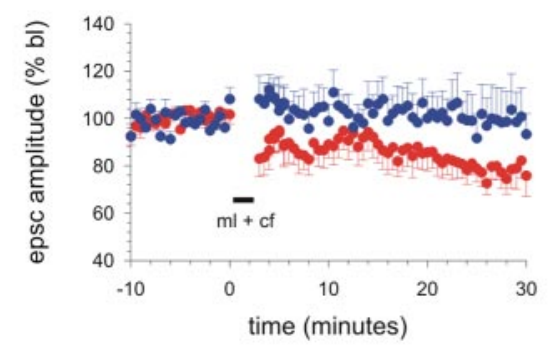

e

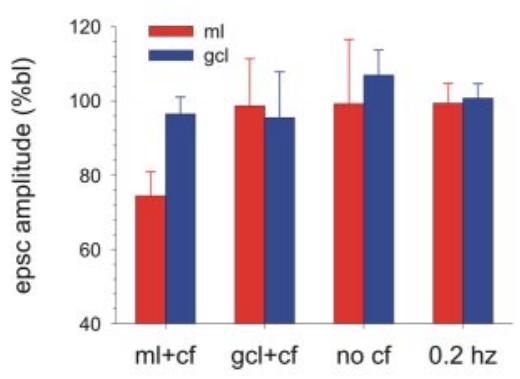

b
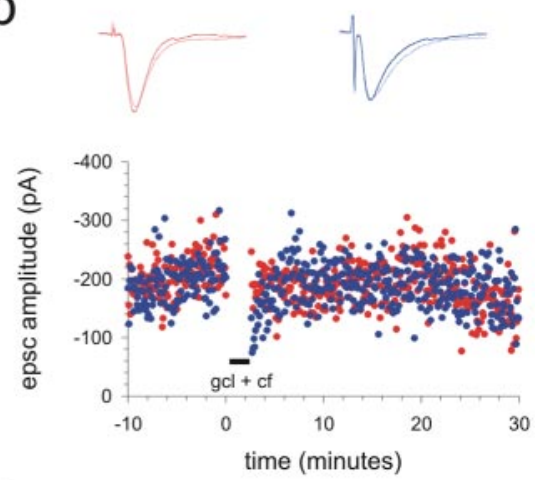

d

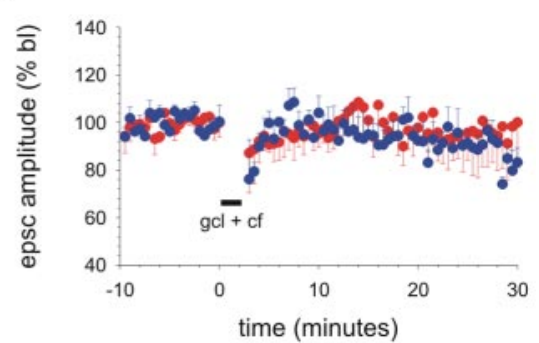

f
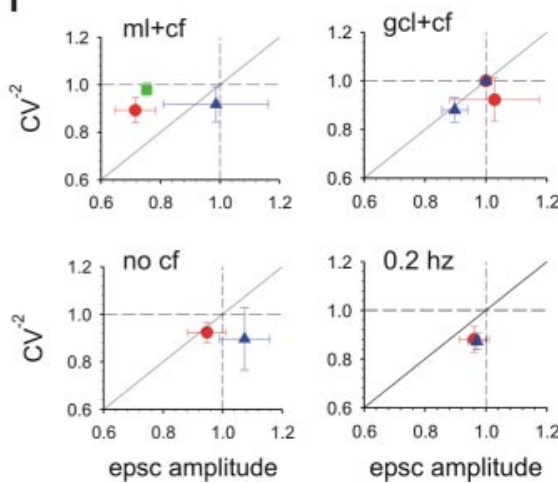

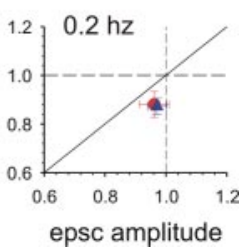

Figure 10. Cerebellar LTD is confined to synapses activated by ML stimulation. Single-cell examples illustrating the effects of conjunctive activation of the CF input with ML stimulation $(\boldsymbol{a})$ and $\mathrm{GCL}$ stimulation $(\boldsymbol{b})$ are shown. In both sets of experiments, stimulation of the alternate pathway was halted during the period of conjunction. Insets are examples of the means of 10 consecutive sweeps sampled midway through the $10 \mathrm{~min}$ baseline period and $30 \mathrm{~min}$ after conjunction. Red and blue traces or circles represent responses to ML and GCL stimulation, respectively. $\boldsymbol{c}$ and $\boldsymbol{d}$ provide pooled data from eight and seven experiments, respectively. The means and SEs of responses to $\mathrm{ML}$ (red) and $\mathrm{GCL}$ (blue) stimulation are shown normalized to baseline levels. $\boldsymbol{e}$, The means and SEs of ML (red) and GCL (blue) EPSC amplitudes sampled 30 min after pairing the CF with the either the $\mathrm{ML}$ or the GCL layer are shown. Data from a series of control experiments in which the ML was activated as in $\boldsymbol{a}$ and $\boldsymbol{b}$ but the (F was not stimulated ( $\mathrm{no} \mathrm{f} ; n=6$ ) and in which both pathways were activated alternatively at $0.2 \mathrm{~Hz}$ throughout $(0.2 \mathrm{~Hz} ; n=6)$ are also shown. $\boldsymbol{f}$ shows the relative changes in $\mathrm{CV}^{-2}$ values plotted against relative changes in mean EPSC amplitudes for each pathway, before and $30 \mathrm{~min}$ after each of the conditions of stimulation outlined in $\boldsymbol{e}$. SEs are also shown. Red circles and blue triangles represent $\mathrm{ML}$ and $\mathrm{GCL}$ responses, respectively. The green square illustrates the relative effect of a decrease in $Q$ from -8.5 to $-6.3 \mathrm{pA}$ using data generated with a standard binomial function.

The combination of higher $P$, higher $Q$, as well as the possibility of multiple synaptic contacts per cell, enables ascending axon synapses to activate PCs situated directly above the termination zone of their afferent mossy fiber inputs with a high degree of reliability. Repetitive stimulation of ascending axon synapses produced only small degrees of facilitation at the second pulse and subsequent pulses declined in amplitude (Fig. 9). In contrast, parallel fiber responses did not decline in amplitude but continued to augment up to the fourth or fifth response before reaching a plateau. Lowering the probability of release led to a much more dramatic facilitation of parallel fiber responses to brief trains of stimuli. Interestingly, these conditions caused ascending axon

synapses to act more like parallel fiber synapses behaved at higher concentrations of external calcium. These data also reveal that the higher probability of release at ascending synapses comes at the expense of a faster rate of depletion. In combination with the lower $Q$, these characteristics permit parallel fibers to act as high-pass filters.

LTD was induced selectively at parallel fiber synapses. This observation is of fundamental importance because it reveals for the first time that not all GC synapses to PCs are equally able to undergo plastic changes at this stage of development in the rat cerebellar cortex, and therefore they should not be considered a homogenous population. Given that LTD was accompanied by a reduction in $Q$ (consistent with the accepted postsynaptic expression of cerebellar LTD), it is tempting to speculate that the lower mean quantal amplitude of parallel fiber synapses is a consequence of LTD and that this accounts for the high proportion of apparently silent or possibly "deaf" synapses encountered along beams of parallel fibers (Isope and Barbour, 2002).

The mechanism of cerebellar synaptic depression is complex but can be simplified into the following three essential elements: LTD requires activation of AMPA receptors, metabotropic glutamate receptors (mGluRs), and postsynaptic calcium influx (Ito, 2001; Hartell, 2002). Because ascending axon and parallel fiber synapses were similarly blocked by NBQX, both pathways are capable of activating AMPA receptors. mGluRs are situated at the periphery of excitatory synapses to PCs (Petralia et al., 1998), and they are activated at higher frequencies of stimulation (Batchelor and Garthwaite, 1997; Finch and Augustine, 1998; Takechi et al., 1998). The reduced ability of ascending axons to undergo PPF and follow higher frequencies of train stimulation may, therefore, make them less able to activate mGluRs. It will be interesting to establish whether mGluRs are expressed similarly at ascending axon and parallel fiber synapses. LTD also requires activation of the $\mathrm{CF}$, which causes a postsynaptic influx of calcium. Because ascending axon synapses form on smaller, more distal synapses (Gundappa-Sulur et al., 1999), it is conceivable that they may fall outside the influence of the CF, which contacts larger, more proximal dendrites (Palay and Chan-Palay, 1974).

The fact that ascending axon synapses were resistant to LTD, as predicted previously (Gundappa-Sulur et al., 1999), further suggests that they serve a fundamentally different role from that of parallel fibers. Whereas ascending axons are essentially hard wired into the cortical sensory circuit and behave like event detectors, parallel fibers have the capacity to undergo both shortand long-term changes in synaptic strength and hence play a 
more dynamic role in modulating cerebellar processing. A recent study showed that GCs have low intrinsic background firing rates, but they reliably undergo high-frequency burst firing on direct stimulation of their sensory receptive fields (Chadderton et al., 2004). According to our findings, which support several predictions based on modeling studies of ascending axon input to PCs (Santamaria et al., 2002), brief bursts of GC activity would be reliably transmitted via ascending axon synapses to PCs directly above the mossy fiber termination zone of sensory input to the receptive field. This therefore extends the remarkable ability of the input layers of the cortex to balance high sensitivity of transmission with high signal-to-noise ratio selectively to PCs contacted by ascending axon synapses. Bursts of GC activity will be further filtered by parallel fiber synapses such that information will be transmitted selectively to those PCs whose synaptic contacts are not silent or in a depressed state. Therefore, at any given point in time, MF information will be transmitted according to the past learned experience of parallel fiber $\rightarrow$ PC synapses, thus maintaining a system for pattern recognition. This network does not, however, preclude additional learning or the reversal of plastic changes, because the repetitive bursts of GC activity required for all forms of plasticity thus far identified at GC $\rightarrow$ PC synapses (including LTD and presynaptic and postsynaptic forms of longterm potentiation) will pass through the parallel fiber filtering system. We would predict from this that ascending axon synapses will be relatively resistant to all forms of GC $\rightarrow$ PC plasticity compared with parallel fiber synapses.

In terms of cerebellar processing, we suggest that ascending axon synapses should now be considered as an entirely separate element of cortical signal processing to parallel fiber synapses in future experimental and theoretical studies of cerebellar signaling and plasticity.

\section{References}

Albus JS (1971) A theory of cerebellar function. Math Biosci 28:167-171.

Anderson WW, Collingridge GL (2001) The LTP program: a data acquisition program for on-line analysis of long-term potentiation and other synaptic events. J Neurosci Methods 108:71-83.

Auger C, Kondo S, Marty A (1998) Multivesicular release at single functional synaptic sites in cerebellar stellate and basket cells. J Neurosci 18:4532-4547.

Axelrad H, Korn H (1982) Field effect and chemical transmission: dual inhibitory action of basket cells in the rat cerebellum cortex. In: The cerebellum: new vistas (Palay SL, Chan-Palay V, eds), pp 412-439. Berlin: Springer.

Barbour B (1993) Synaptic currents evoked in Purkinje cells by stimulating individual granule cells. Neuron 11:759-769.

Barbour B, Isope P (2000) Combining loose cell-attached stimulation and recording. J Neurosci Methods 103:199-208.

Batchelor AM, Garthwaite J (1997) Frequency detection and temporallydispersed synaptic signal association through a metabotropic glutamate receptor pathway. Nature 385:74-77.

Bekkers JM, Stevens CF (1990) Presynaptic mechanism for long-term potentiation in the hippocampus. Nature 346:724-729.

Bower JM, Woolston DC (1983) Congruence of spatial organization of tactile projections to granule cell and Purkinje cell layers of cerebellar hemispheres of the albino rat: vertical organization of cerebellar cortex. J Neurophysiol 49:745-766.

Chadderton P, Margrie TW, Häusser M (2004) Integration of quanta in cerebellar granule cells during sensory processing. Nature 428:856-860.

Clements JD, Silver RA (2000) Unveiling synaptic plasticity: a new graphical and analytical approach. Trends Neurosci 23:105-113.

Clements JD, Lester RA, Tong G, Jahr CE, Westbrook GL (1992) The time course of glutamate in the synaptic cleft. Science 258:1498-1501.

Cohen D, Yarom Y (1998) Patches of synchronized activity in the cerebellar cortex evoked by mossy-fiber stimulation: questioning the role of parallel fibers. Proc Natl Acad Sci USA 95:15032-15036.
Dittman JS, Regehr WG (1996) Contributions of calcium-dependent and calcium-independent mechanisms to presynaptic inhibition at a cerebellar synapse. J Neurosci 16:1623-1633.

Eccles JC, Sasaki K, Strata P (1967) Interpretation of the potential fields generated in the cerebellar cortex by a mossy fibre volley. Exp Brain Res 3:58-80.

Eccles JC, Sabah NH, Schmidt RF, Taborikova H (1972) Integration by Purkyne cells of mossy and climbing fiber inputs from cutaneous mechanoreceptors. Exp Brain Res 15:498-520.

Faber DS, Korn H (1991) Applicability of the coefficient of variation method for analyzing synaptic plasticity. Biophys J 60:1288-1294.

Finch EA, Augustine GJ (1998) Local calcium signalling by inositol-1,4,5trisphosphate in Purkinje cell dendrites. Nature 396:753-756.

Fox CA, Barnard JW (1957) A quantitative study of the Purkinje cell dendritic branchlets and their relationship to afferent fibres. J Anat 91:299-313.

Garwicz M, Andersson G (1992) Spread of synaptic activity along parallel fibres in cat cerebellar anterior lobe. Exp Brain Res 88:615-622.

Gundappa-Sulur G, De Schutter E, Bower JM (1999) Ascending granule cell axon: an important component of cerebellar cortical circuitry. J Comp Neurol 408:580-596.

Hartell NA (2002) Parallel fiber plasticity. Cerebellum 1:3-18.

Harvey RJ, Napper RM (1991) Quantitative studies on the mammalian cerebellum. Prog Neurobiol 36:437-463.

Isope P, Barbour B (2002) Properties of unitary granule cell $\rightarrow$ Purkinje cell synapses in adult rat cerebellar slices. J Neurosci 22:9668-9678.

Ito M (2001) Cerebellar long-term depression: characterisation, signal transduction, and functional roles. Physiol Rev 81:1143-1195.

Ito M (2002) The molecular organization of cerebellar long-term depression. Nat Rev Neurosci 3:896-902.

Jaeger D (2003) No parallel fiber volleys in the cerebellar cortex: evidence from cross-correlation analysis between Purkinje cells in a computer model and in recordings from anesthetized rats. J Comput Neurosci 14:311-327.

Kim J, Alger BE (2001) Random response fluctuations lead to spurious paired-pulse facilitation. J Neurosci 21:9608-9618.

Kocsis JD, Malenka RC, Waxman SG (1983) Effects of extracellular potassium concentration on the excitability of the parallel fibres of the rat cerebellum. J Physiol (Lond) 334:225-244.

Kolb FP, Arnold G, Lerch R, Straka H, Buttner-Ennever J (1997) Spatial distribution of field potential profiles in the cat cerebellar cortex evoked by peripheral and central inputs. Neuroscience 81:1155-1181.

Llano I, Marty A, Armstrong CM, Konnerth A (1991) Synaptic- and agonist-induced excitatory currents of Purkinje cells in rat cerebellar slices. J Physiol (Lond) 434:183-213.

Llinas R (1982) General discussion: radial connectivity in the cerebellar cortex. A novel view regarding the functional organization of the molecular layer. In: The cerebellum: new vistas (Palay SL, Chan-Palay V, eds), pp 189-194. Berlin: Springer.

Marr D (1969) A theory of cerebellar cortex. J Physiol (Lond) 202:437-470.

Matsuda S, Launey T, Mikawa S, Hirai H (2000) Disruption of AMPA receptor GluR2 clusters following long-term depression induction in cerebellar Purkinje neurons. EMBO J 19:2765-2774.

Mugnaini E (1983) The length of cerebellar parallel fibers in chicken and rhesus monkey. J Comp Neurol 220:7-15.

Murthy VN, Sejnowski TJ, Stevens CF (1997) Heterogeneous release properties of visualized individual hippocampal synapses. Neuron 18:599-612.

Napper RM, Harvey RJ (1988) Number of parallel fiber synapses on an individual Purkinje cell in the cerebellum of the rat. J Comp Neurol 274:168-177.

Palay SL, Chan-Palay V (1974) The cerebellar cortex. Cytology and organization. Berlin: Springer.

Perkel DJ, Hestrin S, Sah P, Nicoll RA (1990) Excitatory synaptic currents in Purkinje cells. Proc R Soc Lond B Biol Sci 241:116-121.

Petralia RS, Zhao HM, Wang YX, Wenthold RJ (1998) Variations in the tangential distribution of postsynaptic glutamate receptors in Purkinje cell parallel and climbing fiber synapses during development. Neuropharmacology 37:1321-1334.

Pichitpornchai C, Rawson JA, Rees S (1994) Morphology of parallel fibres in the cerebellar cortex of the rat: an experimental light and electron microscopic study with biocytin. J Comp Neurol 342:206-220. 
Reid CA, Clements JD (1999) Postsynaptic expression of long-term potentiation in the rat dentate gyrus demonstrated by variance-mean analysis. J Physiol (Lond) 518:121-130.

Roth A, Häusser M (2001) Compartmental models of rat cerebellar Purkinje cells based on simultaneous somatic and dendritic patch-clamp recordings. J Physiol (Lond) 535:445-472.

Santamaria F, Jaeger D, De SE, Bower JM (2002) Modulatory effects of parallel fiber and molecular layer interneuron synaptic activity on Purkinje cell responses to ascending segment input: a modeling study. J Comput Neurosci 13:217-235.

Schikorski T, Stevens CF (2001) Morphological correlates of functionally defined synaptic vesicle populations. Nat Neurosci 4:391-395.

Sheardown MJ, Nielsen EO, Hansen AJ, Jacobsen P, Honore T (1990) 2,3Dihydroxy-6-nitro-7-sulfamoyl-benzo(F)quinoxaline: a neuroprotectant for cerebral ischemia. Science 247:571-574.

Shepherd GM, Raastad M, Andersen P (2002) General and variable features of varicosity spacing along unmyelinated axons in the hippocampus and cerebellum. Proc Natl Acad Sci USA 99:6340-6345.

Silver RA, Momiyama A, Cull-Candy SG (1998) Locus of frequencydependent depression identified with multiple-probability fluctuation analysis at rat climbing fibre-Purkinje cell synapses. J Physiol (Lond) 510:881-902.

Takechi H, Eilers J, Konnerth A (1998) A new class of synaptic response involving calcium release in dendritic spines. Nature 396:757-760.

Thomson AM (2000) Facilitation, augmentation and potentiation at central synapses. Trends Neurosci 23:305-312.

Vranesic I, Iijima T, Ichikawa M, Matsumoto G, Knopfel T (1994) Signal transmission in the parallel fiber-Purkinje cell system visualized by highresolution imaging. Proc Natl Acad Sci USA 91:13014-13017.

Wang YT, Linden DJ (2000) Expression of cerebellar long-term depression requires postsynaptic clathrin-mediated endocytosis. Neuron 25:635-647.

Xu-Friedman MA, Harris KM, Regehr WG (2001) Three-dimensional comparison of ultrastructural characteristics at depressing and facilitating synapses onto cerebellar Purkinje cells. J Neurosci 21:6666-6672.

Zhao HM, Wenthold RJ, Wang YX, Petralia RS (1997) Delta-glutamate receptors are differentially distributed at parallel and climbing fiber synapses on Purkinje cells. J Neurochem 68:1041-1052.

Zucker RS (1989) Short-term synaptic plasticity. Annu Rev Neurosci 12:13-31. 